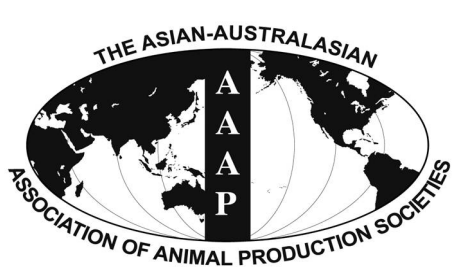

Open Access

Asian Australas. J. Anim. Sci.

Vol. 29, No. 10 : 1477-1482 October 2016

http://dx.doi.org/10.5713/ajas.15.0655

www.ajas.info

pISSN 1011-2367 elSSN 1976-5517

\title{
Effects of Dietary Calcium Levels on Productive Performance, Eggshell Quality and Overall Calcium Status in Aged Laying Hens
}

\author{
S. H. An ${ }^{1}$, D. W. Kim ${ }^{2}$, and B. K. An* \\ Department of Animal Science and Technology, Konkuk University, Seoul 05029, Korea
}

\begin{abstract}
This study was conducted to investigate the effects of diets with varying levels of calcium on egg production, shell quality and overall calcium status in aged laying hens. A total of five hundred 70-wk-old Hy-Line Brown layers were divided five groups and fed one of the five experimental diets with $3.5 \%, 3.8 \%, 4.1 \%, 4.4 \%$, or $4.7 \% \mathrm{Ca}$, for 10 weeks. There were no significant differences in feed intake, egg production and egg weight among groups. The cracked eggs were linearly reduced as dietary Ca levels increased to $4.7 \%(\mathrm{p}<0.01)$. A significant linear improvement for eggshell strength and thickness were determined with increasing dietary $\mathrm{Ca}$ levels $(\mathrm{p}<0.01)$. The contents of serum $\mathrm{Ca}$ and phosphorus were not affected by dietary Ca levels. With increase in dietary $\mathrm{Ca}$ levels, the tibial breaking strength slightly increased. There were no significant differences in the tibial contents of ash, Ca and phosphorus among groups. In conclusion, eggshell quality, as measured by appearance, strength and thickness of eggshell, were influenced by dietary $\mathrm{Ca}$ content as expected $(\mathrm{p}<0.05)$. These results suggested that aged laying hens require relatively higher level of Ca than required levels from current Korean feeding standards for poultry. (Key Words: Dietary Calcium Levels, Cracked Eggs, Eggshell Strength, Tibial Breaking Strength, Aged Laying Hens)
\end{abstract}

\section{INTRODUCTION}

The eggshell quality continues to be a major concern of the egg industry. Eggs with inferior shell quality are a leading economical loss to poultry producers (Roberts, 2004). It has been reported that the average of eggs cracked and lost prior to point of consumption ranged from $13 \%$ to 20\% (Roland, 1988).

The increased incidence of cracked eggs occurs mainly in late laying period. Decrease in eggshell quality of aged laying hens might be attributed to reduced intestinal $\mathrm{Ca}$ uptake and increased egg size (Al-Batshan et al., 1994). Egg size and weight increased with increasing hen age, but it is generally not accompanied by a proportional increase in

\footnotetext{
* Corresponding Author: B. K. An. Tel: +82-2-450-3665, Fax:+82-2-452-9946, E-mail: abk7227@hanmail.net

${ }^{1}$ Team of An Educational Program for Specialists in Global Animal Science, Brain Korea 21 Plus Project, Konkuk University, Seoul 05029, Korea.

${ }^{2}$ Animal Nutrition \& Physiology Team, National Institute of Animal Science, RDA, Wanjugun 55365, Korea.

Submitted Aug. 8, 2015; Revised Nov. 23, 2015; Accepted Jan. 15, 2016
}

shell weight, which leads to a decrease in the shell weight to egg weight ratio. Elaroussi et al. (1994) suggested that the increase in cracked eggs seen in aged layers could be a result of disturbances related with the $\mathrm{Ca}$ homeostasis.

Calcium is one of the key nutrients required for production and optimal eggshell quality of laying hens (Ahmed et al., 2013). Most research reported that a linear improvement in eggshell quality was evident with increasing dietary Ca levels. Roland (1987) also suggested that a linear increase in eggshell quality when feeding dietary $\mathrm{Ca}$ above $4.35 \mathrm{~g} / \mathrm{d}$. On the other hands, Leeson et al. (1993) did not find any effect of higher levels of dietary Ca on eggshell quality and concluded that $3.4 \mathrm{~g}$ of daily $\mathrm{Ca}$ intake was enough for brown egg layers. These discrepancies may be attributed to differences in strains, environmental factors and other nutrients such as phosphorus, which can affect $\mathrm{Ca}$ requirement (Garlich et al., 1984).

To our knowledge, a considerable amount of research has been conducted on the effect of feeding various $\mathrm{Ca}$ levels during early, mid or total laying stage, but only limited information is available on overall $\mathrm{Ca}$ requirement 
drawn from wing vein and analyzed for concentrations of $\mathrm{Ca}$ and phosphorus. The concentrations of serum $\mathrm{Ca}$ and phosphorus were measured according to the colorimetric method using biochemical analyzer (Hitachi modular system, Hitachi Ltd., Tokyo, Japan). At euthanasia, the right legs were immediately collected and stored in the refrigerator for the determination of mechanical property and chemical composition of tibias. Bone breaking strength was measured on fresh tibias using an Instron (Model 3342, Instron Universal Testing Machine, Instron Corp., Norwood, MA, USA) with 50-kg-load cell as 50-kg load range with a crosshead speed of $50 \mathrm{~mm}$ per min with tibia supported on a $3.35 \mathrm{~cm}$ span. The graphs showed the plateau curve of applied maximal force (KN) to measure the tibial strength as expressed as energy stored in the bone. The sheared tibia pieces were collected and deffatted, after which the tibia samples were oven-dried at $100^{\circ} \mathrm{C}$ for $24 \mathrm{~h}$ and then weighted to obtain the dry weight. The tibia samples were ashed in a muffle furnace (Isotemp muffle furnace, Fisher Scientific, Pittsburgh, PA, USA) at $600^{\circ} \mathrm{C}$ for $24 \mathrm{~h}$ in crucibles. The contents of $\mathrm{Ca}$ and phosphorus in tibia were determined using AOAC methods (AOAC, 1995).

\section{Statistical analysis}

Data were analyzed using the general linear model procedures of SAS 9.2 (SAS Inst. Inc., Cary, NC, USA). The cage was considered the experimental unit. Linear, quadratic, or both compared using the orthogonal contrast coefficients. The NLIN procedure of SAS according to Robbins et al. (2006) was used to find optimum breakpoint of Ca level whenever linear and or quadratic effects were significant.

However, all variables only showed the linear effect that is cannot account for optimum breakpoint of $\mathrm{Ca}$ level and therefore proc NLIN procedure was not included in the predictive model. Results were considered significant if their $\mathrm{p}$-values were $<0.05$.

\section{RESULTS AND DISCUSSION}

\section{Egg production}

The feed intake and egg production in aged laying hens fed diets with varying levels of $\mathrm{Ca}$ are presented in Table 2. There were no significant linear and quadratic trends of dietary $\mathrm{Ca}$ levels affecting feed intake, egg production and egg weight. With increasing dietary Ca levels from $3.5 \%$ to $4.7 \%$, cracked eggs linearly reduced $(\mathrm{p}<0.01)$ from $3.6 \%$ to $2.1 \%$.

A number of studies with laying hens have reported that laying performance was not influenced by dietary $\mathrm{Ca}$ levels. Cufadar et al. (2011) did not find any significant differences in egg production and egg weight among the Ca levels of $3.0 \%, 3.6 \%$, or $4.2 \%$ of diets in aged laying hens. Frost and Roland (1991) and Keshavarz and Nakajima (1993) also reported that different levels of dietary $\mathrm{Ca}$ had no significant effect on egg production, egg weight and egg mass. However, an excess of dietary $\mathrm{Ca}$ exerted a negative effect on egg production as a result of reduced feed intake (Ousterhout, 1980; Pelicia et al., 2009).

In present study, the average daily feed intake ranged from $117.1 \mathrm{~g}$ to $120.5 \mathrm{~g}$. The dietary $\mathrm{Ca}$ did not affect the total feed intake in aged layers and had no negative effects on laying performance. There have been contradictory findings in the relationship to feed intake after feeding diets with varying levels of Ca. Olver and Malan (2000) observed that the dietary $\mathrm{Ca}$ levels did not influence total feed intake during 16 to 80 wks of age. Contrary to this, Narvaez-Solarte et al. (2006) reported that daily feed intake was decreased as dietary $\mathrm{Ca}$ levels increased. While Chandramoni et al. (1998) found that with increasing dietary $\mathrm{Ca}$ levels, the daily feed intake tended to be increase, but not significantly. This discrepancy may be attributed to differences in age of bird, dietary energy density and feeding levels of $\mathrm{Ca}$.

A significant linear decrease in incidence of cracked egg was evident with increasing dietary $\mathrm{Ca}$ (Table 3 ). This decrease in incidence of cracked egg might be associated with improvement in eggshell strength and thickness seen according to increasing dietary $\mathrm{Ca}$. The intake of insufficient amounts of $\mathrm{Ca}$ may cause poor shell quality, leading to higher incidence of cracked eggs (Jiang et al., 2013). In this study, the feed intake was not affected by dietary $\mathrm{Ca}$ levels during overall experimental period, whereas the tentative total $\mathrm{Ca}$ intake was increased as

Table 3. Effect of graded levels of dietary calcium on production performance in the aged laying hens s $^{1,2}$

\begin{tabular}{|c|c|c|c|c|c|c|c|c|}
\hline \multirow{2}{*}{ Item } & \multicolumn{5}{|c|}{ Level of $\mathrm{Ca}(\%)$} & \multirow{2}{*}{ SEM } & \multicolumn{2}{|c|}{ p-value } \\
\hline & 3.5 & 3.8 & 4.1 & 4.4 & 4.7 & & Linear & Quadratic \\
\hline Feed intake ( $\mathrm{g} / \mathrm{d} / \mathrm{bird})$ & 120.5 & 117.5 & 117.8 & 117.1 & 118.6 & 2.06 & 0.517 & 0.319 \\
\hline Egg production (\%) & 75.1 & 76.0 & 75.2 & 75.0 & 79.1 & 1.43 & 0.134 & 0.197 \\
\hline Egg weight (g/egg) & 60.4 & 60.3 & 61.0 & 60.8 & 61.2 & 0.64 & 0.223 & 0.486 \\
\hline Cracked egg (\%) & 3.6 & 3.4 & 2.3 & 2.2 & 2.1 & 0.46 & 0.007 & 0.475 \\
\hline
\end{tabular}

SEM, standard error of the means.

${ }^{1}$ Data are least square of mean of 10 replicate with 5 cages with 2 birds per cage.

${ }^{2}$ Mean values from the overall experimental period. 
Table 4. Effect of graded levels of dietary calcium on egg and eggshell qualities in aged laying hens ${ }^{1,2}$

\begin{tabular}{|c|c|c|c|c|c|c|c|c|}
\hline \multirow{2}{*}{ Item } & \multicolumn{5}{|c|}{ Level of $\mathrm{Ca}(\%)$} & \multirow{2}{*}{ SEM } & \multicolumn{2}{|c|}{ p-value } \\
\hline & 3.5 & 3.8 & 4.1 & 4.4 & 4.7 & & Linear & Quadratic \\
\hline Eggshell color $^{3}$ & 38.7 & 38.4 & 38.5 & 38.3 & 37.6 & 0.71 & 0.312 & 0.704 \\
\hline Yolk color $^{4}$ & 5.0 & 5.1 & 5.3 & 5.4 & 5.5 & 0.14 & $<0.001$ & 0.429 \\
\hline Eggshell strength $^{5}$ & 2.25 & 2.31 & 2.37 & 2.37 & 2.46 & 0.05 & 0.003 & 0.994 \\
\hline Eggshell thickness ${ }^{6}$ & 34.8 & 35.1 & 35.1 & 36.6 & 36.0 & 0.52 & 0.006 & 0.890 \\
\hline Haugh unit ${ }^{7}$ & 76.55 & 72.64 & 75.07 & 72.59 & 73.89 & 1.44 & 0.237 & 0.305 \\
\hline
\end{tabular}

SEM, standard error of the means; TSS, Technical Services and Supplies Ltd., York, England.

${ }^{1}$ Data are least square of mean of 10 replicate with 5 cages with 2 birds per cage. ${ }^{2}$ Mean values from the 76 or 78 to 80 weeks of age.

${ }^{3}$ Eggshell color is measured by Egg multi tester made by TSS. ${ }^{4}$ Yolk color is measured by Roche yolk color fan.

${ }^{5}$ Eggshell strength measurement is expressed as $\mathrm{kg} / \mathrm{cm}^{2} .{ }^{6}$ Eggshell thickness measurement is expressed as $0.01 \mathrm{~mm}$.

${ }^{7}$ Haugh unit value is determined using the procedure described by Haugh $(1937) . \mathrm{HU}=100 \times \log \left(\mathrm{H}-1.7 \times \mathrm{w}^{0.37}+7.6\right)$, where: $\mathrm{H}=$ albumen height, mm; w $=$ egg weight, $g$.

dietary $\mathrm{Ca}$ increased. To minimize the incidence rates of cracked eggs in aged layers, the diet must supply enough $\mathrm{Ca}$ due to the effect being linear.

\section{Eggshell qualities}

The egg and eggshell qualities in aged laying hens fed diets with varying levels of $\mathrm{Ca}$ are presented in Table 4. There were no significant linear and quadratic trends of dietary $\mathrm{Ca}$ levels affecting eggshell color and Haugh unit. Yolk color score was linearly increased as dietary Ca level increased, although the reason for the difference was not explainable. The eggshell quality was influenced by dietary $\mathrm{Ca}$, as expected. The strength and thickness of eggshell were significantly increased $(p<0.01)$ by dietary Ca levels in a linear manner (Table 4).

The available results about effect of dietary Ca levels on eggshell qualities are somewhat inconsistent. Jiang et al. (2013) found that layers on a diet with $2.62 \% \mathrm{Ca}$ had a weaker eggshell breaking strength than those on a diet with $3.7 \%$ or $4.4 \%$ Ca. Roland (1987) suggested that the eggshell quality was linearly increased when dietary $\mathrm{Ca}$ levels were above $4.35 \mathrm{~g}$ per day. On the other hands, Keshavarz and Nakajima (1993) reported that increasing levels of dietary calcium from $3.5 \%$ to $5.5 \%$ did not have any beneficial effects on eggshell qualities in a long-term experiment. Cufadar et al. (2011) also noted that the level of dietary $\mathrm{Ca}$ had no significant effect on eggshell breaking strength and eggshell thickness.

The adequacy of recommended amounts of dietary $\mathrm{Ca}$ for optimal eggshell qualities is still being studied. But, based on the results obtained from previous studies, a constant increase in the level of dietary $\mathrm{Ca}$ has been associated with improvement of laying performance. Castillo et al. (2004) reported that the biological optimum level for maximum eggshell quality (as specific gravity) was $4.62 \% \mathrm{Ca}$ in diet. An increase in Ca intake from 4.08 to $4.64 \mathrm{~g} / \mathrm{d}$ improved the eggshell weight and eggshell thickness in aged Brown layers (Safaa et al., 2008), which is consistent with results of this study. Also, the research results led to the definition of a linear effect on dietary $\mathrm{Ca}$ with the eggshell quality. Pelicia (2009) reported that using 90 and 108 weeks of age laying hens, there was no effects of dietary $\mathrm{Ca}$ on eggshell strength and thickness; but the eggshell percentage and eggshell weight per surface area (ESWSA) was increased by increasing $\mathrm{Ca}$ concentration in the diet. And they obtained linear regression equation $\mathrm{y}=$ $0.119 x+8.9985 ; R^{2}=0.899$ in eggshell percentage and $y=$ $1.5879 x+78.556 ; R^{2}=0.886$ in ESWSA. Likewise, the present study showed linear effect in the eggshell strength and eggshell thickness. The determined linear regression equations of the effect of dietary $\mathrm{Ca}$ on eggshell strength $\mathrm{y}$ $=0.16 \mathrm{x}+1.70 ; \mathrm{R}^{2}=0.941$ and on eggshell thickness $\mathrm{y}=$ $1.31 \mathrm{x}+30.14 ; \mathrm{R}^{2}=0.656$ showed that both eggshell strength and thickness linearly increase as dietary $\mathrm{Ca}$ intake increased. Through these results, we consider that dietary $\mathrm{Ca}$ has a strong linear relationship to eggshell strength.

The NRC (1994) suggested the Ca requirement of Brown layers to be $3.4 \%$ of dietary Ca for $110 \mathrm{~g} / \mathrm{d}$ feed intake regardless of age, which seems inadequate for optimal eggshell qualities. More recently, the Korean feeding standard for poultry (2012) proposed the Ca requirement for aged Brown layers up to $4.1 \%$ at a feed intake of $110 \mathrm{~g} / \mathrm{d}$. The maximum requirement for calcium based on eggshell qualities is uncertain due to the effect being linear in present study. Obviously, aged Brown layers require considerably higher level of $\mathrm{Ca}$ to optimize eggshell quality than suggested levels in previous studies.

The inclusion of conventional phytase in layer diets has been greatly increased, in response to reduce the feed and production costs and to minimize phosphorus excretion. There is evidence that phytase positively influences the digestion and absorption of $\mathrm{Ca}$, although the available results about dietary phytase did not have any consistent effects on the eggshell qualities. Punna and Roland (1999) observed a beneficial effect on eggshell quality of phytase inclusion, but others did not find any effect (Parsons, 1999). The possibility of positive effect by dietary phytase should not be precluded and further study is needed to clarify 
Table 5. Effect of graded levels of dietary calcium on overall calcium status in serum and tibia ${ }^{1,2}$

\begin{tabular}{|c|c|c|c|c|c|c|c|c|}
\hline \multirow{2}{*}{ Item } & \multicolumn{5}{|c|}{ Level of $\mathrm{Ca}(\%)$} & \multirow{2}{*}{ SEM } & \multicolumn{2}{|c|}{ p-value } \\
\hline & 3.5 & 3.8 & 4.1 & 4.4 & 4.7 & & Linear & Quadratic \\
\hline \multicolumn{9}{|l|}{ Serum $(\mathrm{mg} / \mathrm{dL})$} \\
\hline Calcium & 28.9 & 30.2 & 29.6 & 27.2 & 29.0 & 1.20 & 0.488 & 0.561 \\
\hline Phosphorus & 6.55 & 6.53 & 6.37 & 5.99 & 6.11 & 0.41 & 0.274 & 0.815 \\
\hline \multicolumn{9}{|l|}{ Tibia } \\
\hline Length (cm) & 11.61 & 11.88 & 11.78 & 11.66 & 11.98 & 0.13 & 0.233 & 0.876 \\
\hline Strength ${ }^{3}$ & 16.15 & 17.50 & 17.47 & 17.58 & 18.43 & 0.99 & 0.148 & 0.818 \\
\hline Ash (\%) & 48.83 & 45.85 & 45.86 & 46.57 & 46.84 & 1.24 & 0.408 & 0.912 \\
\hline Calcium (\%) & 17.79 & 17.26 & 17.68 & 18.16 & 18.25 & 0.48 & 0.234 & 0.917 \\
\hline Phosphorus (\%) & 9.19 & 8.69 & 8.55 & 9.27 & 9.33 & 0.24 & 0.253 & 0.317 \\
\hline
\end{tabular}

SEM, standard error of the means.

${ }^{1}$ Data are least square of mean of 10 replicate with 1 hen per each replicate. ${ }^{2}$ Mean values at 80 weeks of age.

${ }^{3}$ Breaking strength measurements is expressed as $\mathrm{kg} / \mathrm{mm}^{2}$.

dietary Ca levels on eggshell quality, depending on whether or not conventional phytase.

\section{Overall calcium status}

There were no significant linear and quadratic trends of dietary $\mathrm{Ca}$ levels affecting concentration of serum $\mathrm{Ca}$ and phosphorus (Table 5). Contrary to this, Frost and Roland (1991) reported that the level of plasma ionized Ca was significantly increased in a linear manner by increasing dietary Ca levels from $2.75 \%$ to $4.25 \%$, but not plasma total calcium.

With increase in dietary Ca levels, the tibial breaking strength tended to be increased, but not significantly. There were no significant linear or quadratic trends of dietary $\mathrm{Ca}$ affecting ash, $\mathrm{Ca}$ and phosphorus contents in tibia among groups (Table 5). This result is consistent with that of Jiang et al. (2013), who reported that the hens fed diet with $4.4 \%$ $\mathrm{Ca}$ had similar bone density and strength as compared with those of diet with $3.7 \% \mathrm{Ca}$. Contrary to these results, a study has shown that increasing dietary Ca level linearly increased bone strength (Roland et al., 1996). Koutoulis et al. (2009) also suggested that increasing dietary Ca levels from $3.5 \%$ to $4.0 \%$ significantly increased tibial breaking strength in Brown layers at 72 wks of age. The reason for this discrepancy among authors with respect to bone status is not apparent, but might be attributed to differences in age, strain, dietary $\mathrm{Ca}$ levels and nutrient specification of experimental diets.

On the basis of present results, the dietary Ca levels did not affect on the total feed intake and laying performance in aged laying hens. But, the eggshell quality can be improved by ingesting more $\mathrm{Ca}$, up to $4.7 \%$, during last third of total laying period. In summary, our results indicate that aged Brown layers require relatively higher level of $\mathrm{Ca}$ to reduce cracked eggs and to maximize eggshell qualities than required levels, $4.1 \%$ of diet, from current Korean feeding standards for poultry.

\section{CONFLICT OF INTEREST}

We certify that there is no conflict of interest with any financial organization regarding the material discussed in the manuscript.

\section{ACKNOWLEDGMENTS}

This paper was supported by the KU Research Professor Program of Konkuk University. The results were obtained with financial support of National Institute of Animal Science, RDA.

\section{REFERENCES}

Ahmed, N. M., K. A. Abdel Atti, K. M. Elamin, K. Y. Dafalla, H. E. E. Malik, and B. M. Dousa. 2013. Effect of dietary calcium sources on laying hens performance and egg quality. J. Anim. Prod. Adv. 3:226-231.

Al-Batshan, H. A., S. E. Sceideler, B. L. Black, J. D. Garlich, and K. E. Anderson. 1994. Duodenal calcium uptake, femur ash and eggshell quality decline with age and increase following molt. Poult. Sci. 73:1590-1596.

An, B. K., H. S. Kwon, B. K. Lee, J. Y. Kim, S. J. You, J. M. Kim, and C. W. Kang. 2010. Effects of dietary skullcap (Scutellaria baicalensis) extract on laying performance and lipid oxidation of chicken eggs. Asian Australas. J. Anim. Sci. 23:772-776.

AOAC (Association of Official Analytical Chemists) International. 1995. Official Methods of Analysis of AOAC International, 16th edn. AOAC International, Gaithersburg, MD, USA.

Castillo, C., M. Cuca, A. Pro, M. González, and E. Morales. 2004. Biological and economic optimum level of calcium in White Leghorn laying hens. Poult. Sci. 83:868-872.

Chandramoni, S. B. Jadhao, and R. P. Sinha. 1998. Effect of dietary calcium and phosphorus concentrations on retention of these nutrients by caged layers. Br. Poult. Sci. 39:544-548.

Cufadar, Y., O. Olgun, and A. O. Yildiz. 2011. The effect of dietary calcium concentration and particle size on performance, eggshell quality, bone mechanical properties and tibia mineral contents in moulted laying hens. Br. Poult. Sci. 52:761-768. 
Elaroussi, M. A., L. R. Forte, S. L. Eber, and H. V. Biellier. 1994. Calcium homeostasis in the laying hen. 1. Age and dietary calcium effects. Poult. Sci. 73:1581-1589.

Frost, T. J. and D. A. Roland, Sr. 1991. The influence of various calcium, and phosphorus levels on tibia strength, and eggshell quality of pullets during peak production. Poult. Sci. 70:963969.

Garlich, J., J. Brake, C. R. Parkhurst, J. P. Thaxton, and G. W. Morgan. 1984. Physiological profile of caged layers during one production year, molt and postmolt: Egg production, eggshell quality, liver, femur, blood parameters. Poult. Sci. 63:339-343.

Haugh, R. R. 1937. The Haugh unit for measuring egg quality. US Egg Poult. Mag. 43:552-573.

Jiang, S., L. Cui, C. Shi, X. Ke, J. Luo, and J. Hou. 2013. Effects of dietary energy and calcium levels on performance, egg shell quality and bone metabolism in hens. Vet. J. 198:252-258.

Keshavarz, K. and S. Nakajima. 1993. Re-evaluation of calcium and phosphorus requirements of laying hens for optimum performance and eggshell quality. Poult. Sci. 72:144-153.

Korean Feeding Standard for Poultry. 2012. Nutrient Requirement of Poultry. National Institute of Animal Science, RDA, Suwon, Korea.

Koutoulis, K. C., I. Kyriazakis, G. C. Perry, and P. D. Lewis. 2009. Effect of different calcium sources and calcium intake on shell quality and bone characteristics of laying hens at sexual maturity and end of lay. Int. J. Poult. Sci. 8:342-348.

Leeson, S., J. D. Summers, and L. Caston. 1993. Response of brown-egg strain layers to dietary calcium or phosphorus. Poult. Sci. 72:1510-1514.

Narvaez-Solarte, W., H. S. Rostagno, P. R. Soares, L. F. UribeVelasquez, and M. A. Silva. 2006. Nutritional requirement of calcium in white laying hens from 46 to 62 wk of age. Int. J. Poult. Sci. 5:181-184.

NRC (National Research Council). 1994. Nutrient Requirements of Poultry. 9th edn. National Academy Press, Washington, DC, USA.
Olver, M. D. and D. D. Malan. 2000. The effect of choice-feeding from 7 weeks of age on the production characteristics of laying hens. S. Afr. J. Anim. Sci. 30:110-114.

Ousterhout, L. E. 1980. Effect of calcium and phosphorus levels on egg weight and eggshell quality in laying hens. Poult. Sci. 59:1480-1484.

Parsons, C. M. 1999. The Effect of Dietary Available Phosphorus and Phytase Level on Long-term Performance of Laying Hens. BASF Corp., Florham Park, NJ, USA. pp. 24-33.

Pelicia, K., E. Gracia, C. Mori, A. B. G. Faitarone, A. P. Silva, A. B. Molino, F. Vercese, and D. A. Berto. 2009. Calcium levels and limestone particle size in the diet of commercial layers at the end of the first production cycle. Rev. Bras. Cienc. Avic. 11:87-94.

Punna, S. and D. A. Roland, Sr. 1999. Influence of supplemental microbial phytase on first cycle laying hens fed phosphorusdeficient diets from day one of age. Poult. Sci. 78:1407-1411.

Robbins, K. R., A. M. Saxton, and L. L. Southern. 2006. Estimation of nutrient requirements using broken-line regression analysis. J. Anim. Sci. 84:E155-E165.

Roberts, J. R. 2004. Factors affecting egg internal quality and eggshell quality in laying hens. J. Poult. Sci. 41:161-177.

Roland, Sr., D. A. 1987. Calcium and other factors involved in maintaining eggshell quality in commercial Leghorns. In: Proceedings of the Arkansas Nutrition Conference, Little Rock, AR, USA. pp. 96-100.

Roland, Sr., D. A. 1988. Research note: Egg shell problems: Estimates of incidence and economic impact. Poult. Sci. 67:1801-1803.

Roland, Sr., D. A., M. M. Bryant, and H. W. Rabon. 1996. Influence of calcium and environmental temperature on performance of first cycle (Phase 1) commercial leghorns. Poult. Sci. 75:62-68

Safaa, H. M., M. P. Serrano., D. G. Valencia, M. Frikha, E. Jimenez-Moreno, and G. G. Mateos. 2008. Productive performance and egg quality of brown egg-laying hens in the late phase of production as influenced by level and source of calcium in the diet. Poult. Sci. 87:2043-2051. 